\title{
HIV and other sexually transmitted diseases at a rural hospital in Zimbabwe
}

Franky Le Bacq, Peter R Mason, Lovemore Gwanzura, Valerie J Robertson, Ahmed S Latif

\begin{abstract}
Objective-To define the epidemiological characteristics of STD patients attending an outpatient clinic in rural Zimbabwe, to examine the aetiologic agents causing infection and to determine their relationship with HIV infection.

Subjects-319 men and 146 women, making a sample of about $7 \%$ all patients attending an STD clinic during the 3 month study period. Microbiological data were collected from 104 men and 72 women selected randomly from these. Pregnant women were excluded and patients who had received antibiotics within the previous 14 days were excluded from the microbiology subsample.
\end{abstract}

Setting-An outpatient STD clinic at a District Hospital on a major truck route about $300 \mathrm{~km}$ north of the capital, Harare.

Methods-All new patients attending the clinic during a 3 month period were enrolled for clinical and epidemiological investigations using a standard procedure. Specimens for microbiological investigation were taken from every second patient seen on the first three days of each week.

Results-The typical patient was male (m:f ratio $2 \cdot 2$ ) aged $20-29$ years $(68 \%$ patients), not married (56\% men) and in paid employment ( $66 \%$ men vs. $27 \%$ for the district). In men the most common presenting feature was genital ulceration, while in women, discharges were more common. Genital warts were noted frequently in both sexes. In the sub-sample examined microbiologically, $H$ ducreyi was isolated from $46 \%$ ulcers clinically diagnosed as chancroid, and motile spirochaetes were detected in $25 \%$ painless ulcers. Neither of these were detected in ulcers in women, but HSV antigen was found as frequently in ulcers from men $(19 \%)$ as from women $(17 \%)$. In patients with genital discharges, gonococcal infection occurred in $64 \%$ men and $17 \%$ women, while $T$ vaginalis was isolated from $39 \%$ women and only $8 \%$ men. Over $60 \%$ gonococcal isolates were PPNG, and $18 \%$ showed in vitro resistance to tetracycline. Yeasts, mainly $C$ albicans were isolated from $42 \%$ women with a discharge and $25 \%$ women with ulcers. In men the presence of yeasts was associated with superficial ulceration and itchiness of the glans. Positive HIV-1 serology was found in $64 \%$ patients. There was no statistical association with current genital ulcers, though there was an association with previous STD episodes and particularly with serological evidence of syphilis. Apart from yeasts, there was no association between positive HIV-1 serology and the presence of pathogens in the genital tract.

Conclusions-The high prevalence of HIV-1 antibodies in STD patients in Karoi suggests integration of STD and AIDS control programmes to be a necessity. Since paid employment was a common feature of both STD clinic attendance and HIV-1 seropositivity, these programmes may be effectively directed through the work place.

(Genitourin Med 1993;69:352-356)

\section{Introduction}

Sexually transmitted diseases are a significant public health problem in both urban and rural areas of Africa. ${ }^{1}$ They occur commonly, have a major effect on maternal-child health and may require the allocation of a substantial proportion of the health budget. In Zimbabwe, annual reports from the two major urban centres, Harare and Bulawayo, have noted an increasing frequency of reported cases of STD over the last decade ${ }^{23}$ and in 1990 over one million STD infections were treated. Similar data may be obtained in rural communities. In Karoi District, a mainly agricultural district some $200 \mathrm{~km}$ north of Harare, the number of STD cases rose from just over 13000 in 1986 to almost 20000 in 1990. The district has an adult population estimated at $140000^{4}$ making a reported incidence of about 14 cases per 100 people annually. STDs make up about $11 \%$ of all new cases seen at the District Hospital, being the second most common complaint in adults attending out-patient clinics.

The shortage of laboratory facilities and personnel at rural health centres means that most infections are diagnosed clinically. Accurate data on STD aetiology in Zimbabwe have been reported only for patients attending a referral centre in the capital, ${ }^{5}$ and as part of a programme on STD in rural centres, we investigated new cases presenting at Karoi District Hospital during a three month period. The data we present here cover clinical and epidemiological characteristics of all patients, and the results of microbiological investigations on a representative sample of these. 
Materials and methods

Patient selection

All new patients presenting to the outpatient department of Karoi District Hospital with suspected STD during March to May 1991 were enrolled in the study. Patients were given a thorough clinical examination and a standard questionnaire was taken for details of past history, with particular regard to previous STD and treatments. Women who were suspected to be pregnant were referred to the ante-natal rather than the STD clinic, and so were excluded.

Because of limited finance and facilities, microbiological data were collected on a subsample selected as every second patient seen at the clinic during the first three days of each week. Patients who had documentary evidence of antibiotic treatment within the past two weeks were excluded, despite having symptoms, because of the effect this may have had on the microbial flora. No specimens were taken from asymptomatic patients because of ethical and financial constraints.

\section{Specimen collection}

Cotton tipped swabs were used to collect specimens of urethral, vaginal and/or cervical discharge from men and women. These were inoculated immediately on to Thayer-Martin agar for gonococci, and then into Diamond's medium for maintenance of Trichomonas vaginalis and yeasts. For the latter, a drop of the medium was subsequently inoculated on to Sabourauds dextrose agar (SDA) with 50 $\mathrm{mg} / \mathrm{l}$ chloramphenicol. A second swab was taken into transport medium for detection of chlamydial antigen (Chlamydiazyme, Abbott Labs, USA). Genital ulcers were irrigated with about $2 \mathrm{ml}$ sterile saline and the washing was injected into a sterile bottle. A drop of this fluid was examined by dark ground microscopy within 10 mins. Further samples were inoculated onto two media (MuellerHinton agar with $3 \mathrm{mg} / 1$ vancomycin, horse blood and isovitalex, and Brain-Heart Infusion containing $10 \%$ foetal bovine serum plus $3 \mathrm{mg} / 1$ vancomycin) for isolation of Haemophilus ducreyi. ${ }^{6}$ A second drop was inoculated onto SDA with chloramphenicol for yeasts. Smears were prepared on glass slides, fixed in acetone and stored at $-20^{\circ} \mathrm{C}$ for detection of herpes simplex virus types I and II (HSV) using fluorescein labelled monoclonal antibody (provided by California State Dept Health Services, Berkeley, USA). For women with a discharge, the vaginal vault was irrigated with about $2 \mathrm{ml}$ sterile saline, and the saline-discharge mixture was injected into a sterile bottle. This was used to inoculate SDA for yeasts and Diamond's medium for trichomonas as above, and to inoculate selective agar for Gardnerella vaginalis (Mast Labs. UK). A drop of the salinedischarge was examined microscopically for "clue cells". Initial cultures were set up at Karoi, within two hours of specimen collection, and were transported to Harare each week for final identification.

Clotted blood was taken from each patient, and the serum separated and stored at $-20^{\circ} \mathrm{C}$. Sera were subsequently tested for antibody to HIV-1 by a single ELISA (Abbott Labs, USA), and by RPR, TPHA and FTAAbs for syphilis serology.

\section{Microbial identification}

All cultures were incubated under appropriate atmospheric and temperature conditions. Neisseria gonorrhoeae was identified on the basis of colony morphology, Gram stain, oxidase activity and utilisation of glucose but not maltose. All isolates were tested for $\beta$-lactamase (Intralactam, Mast Labs, UK) and for disc sensitivity to penicillin $G$ (2 units) and tetracycline $(25 \mathrm{ug})$. Diamond's cultures were examined daily for 3 days, and $T$ vaginalis was identified by microscopy. $H$ ducreyi was identified on the basis of colony morphology, including a "push test", Gram stain and negative porphyrin test. Gram negative, metronidazole sensitive organisms growing on selective medium and able to hydrolyse starch and raffinose were identified as $G$ vaginalis. Yeasts were tested for germ tube production, and negative isolates were identified using commercial tests (API Systems, France).

\section{Statistics}

The data were recorded on database for analysis by either chi square or Fisher's exact test. Probabilities are recorded as $<0.01$, $<0.05$ or not significant (NS).

\section{Results}

Patients

In all 465 patients were enrolled, making about $7 \%$ of all outpatients at Karoi District Hospital during the study period. There were 319 men and 146 women, giving a male:female ratio of $2 \cdot 2$. The age and gender distribution is shown in table 1 . Eighty nine $(61 \%)$ women claimed to be married, compared with $139(44 \%)$ men $(p<0.01)$. The mean age of married men was 31 years compared with 24 years for unmarried men ( $p<$ 0.01 ), but there was no significant difference in the mean ages of married (26 years) and unmarried (25 years) women. The majority of women $(121,83 \%)$ were not in paid employment, while the majority of men (210, $66 \%$ ) were employed either in town or on surrounding commercial farms.

There was a previous STD history in 86 (59\%) women and 235 (74\%) men, though data on the exact nature of the STD were not

Table 1 Age and gender distribution of new STD patients at Karoi District Hospital, March-May 1991

\begin{tabular}{|c|c|c|c|}
\hline \multirow[b]{2}{*}{ Age (years) } & \multicolumn{2}{|l|}{ No. (\%) } & \multirow{2}{*}{$\begin{array}{l}\text { M:F ratio } \\
\left(\text { District }{ }^{*}\right)\end{array}$} \\
\hline & Women & Men & \\
\hline $\begin{array}{l}10-19 \\
20-29 \\
30-39 \\
40+ \\
\text { NRt } \\
\text { Total }\end{array}$ & $\begin{array}{r}15(10 \%) \\
100(69 \%) \\
21(14 \%) \\
4(3 \%) \\
6(4 \%) \\
146\end{array}$ & $\begin{array}{r}19(25 \%) \\
214(67 \%) \\
58(18 \%) \\
24(8 \%) \\
4(1 \%) \\
319\end{array}$ & $\begin{array}{l}1 \cdot 3(1 \cdot 0) \\
2 \cdot 1(0 \cdot 8) \\
2 \cdot 8(0.9) \\
6 \cdot 0(1 \cdot 2)\end{array}$ \\
\hline
\end{tabular}

${ }^{\star} \mathrm{M}: \mathrm{F}$ ratio for the district (see ref. 4). tNR = not recorded. 
Table 2 Clinical findings in STD patients

\begin{tabular}{|c|c|c|c|}
\hline \multirow{2}{*}{$\begin{array}{l}\text { Clinical findings/ } \\
\text { diagnosis }\end{array}$} & \multicolumn{2}{|l|}{ No. (\%) } & \multirow[b]{2}{*}{$p^{*}$} \\
\hline & Men & Women & \\
\hline $\begin{array}{l}\text { Genital ulcer } \\
\text { painful }\end{array}$ & $202(63 \%)$ & $35(24 \%)$ & $<0.01$ \\
\hline $\begin{array}{l}\text { with bubo } \\
\text { without bubo } \\
\text { painless }\end{array}$ & $\begin{array}{r}137(43 \%) \\
41(13 \%) \\
65(20 \%)\end{array}$ & $\begin{array}{c}28(19 \%) \\
4(3 \%) \\
7(5 \%)\end{array}$ & $\begin{array}{l}<0.01 \\
<0.01 \\
<0.01\end{array}$ \\
\hline $\begin{array}{l}\text { Genital discharge } \\
\text { vaginal } \\
\text { cervical }\end{array}$ & $88(28 \%)$ & $\begin{array}{r}114(79 \%) \\
89(61 \%) \\
41(28 \%)\end{array}$ & $<0.01$ \\
\hline $\begin{array}{l}\text { Generalised } \\
\text { lymphadenopathy }\end{array}$ & $207(65 \%)$ & $60(41 \%)$ & $<0.01$ \\
\hline $\begin{array}{l}\text { Lymphogranuloma } \\
\text { venereum }\end{array}$ & $11(3 \%)$ & $4(3 \%)$ & NS \\
\hline $\begin{array}{l}\text { Genital warts } \\
\text { Acute orchitis }\end{array}$ & $\begin{array}{l}39(12 \%) \\
13(4 \%)\end{array}$ & $19(13 \%)$ & NS \\
\hline
\end{tabular}

${ }^{\star}$ Comparing male and female.

always available and so these were omitted from data analysis. A history of previous STD was found in $76 \%$ wage earners, $75 \%$ commercial farm workers and $62 \%$ unemployed people $(p<0.05)$. Employed patients came for treatment sooner than unemployed patients (median 7 vs 14 days resp. $\mathrm{p}<0.01$ ).

\section{Clinical findings}

Genital ulcer disease (GUD) was by far the most common presentation in men, while discharge was more common in women (table 2). In men and women with GUD the number of ulcers was similar (range 1-17 for women, 1-30 for men, mean 4 in both) and more than two thirds of the patients described the ulcers as painful. Ulcers were indurated in $47 \%$ cases in men, compared with $23 \%$ cases in women $(p<0.01)$. In men the ulcers were most commonly on the sulcus $(46 \%)$, foreskin $(37 \%)$ and frenulum $(21 \%)$, and less frequently on the glans, shaft or urethra. In women, most ulcers were located on the labia $(80 \%)$ and/or fourchette $(54 \%)$ but rarely on the perineum, vagina or clitoris.

At least one inguinal bubo was found in $20 \%$ men and $6 \%$ women, being unilateral in the great majority of these. Longitudinal superficial ulceration of the foreskin, "rhagades", were noted in 18 (6\%) men. Itchiness of the glans was reported by 33 $(10 \%)$, and secondary phimosis was found in $42(13 \%)$ men. Enlarged lymph nodes in at least two extrainguinal sites were recorded for two thirds of the men, but less than half the women. Oral candidiasis was found in only two (male) patients.

Multiple clinical diagnoses were made for $34(23 \%)$ women and $42(13 \%)$ men $(p<$ $0.01)$. None of the women, and only two of the men had been circumcised.

Treatment history

Before coming to the hospital many men $(42 \%)$ and women $(40 \%)$ had been treated

Table 4 Results of syphilis serology

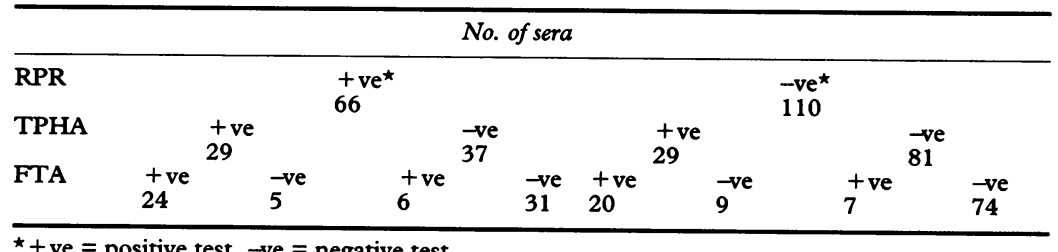

Table 3 Isolation of pathogens from STD patients

\begin{tabular}{|c|c|c|}
\hline & \multicolumn{2}{|c|}{ No. (\%) patients with discharge } \\
\hline & $\operatorname{Men}(n=36)$ & Women $(n=65)$ \\
\hline \multirow[t]{3}{*}{$\begin{array}{l}N \text { gonorrhoeae } \\
T \text { vaginalis } \\
\text { Chlamydia antigen } \\
G \text { vaginalis } \\
\text { Yeasts }\end{array}$} & $\begin{array}{l}23(64 \%) \\
3(8 \%) \\
3(8 \%) \\
- \\
-\end{array}$ & $\begin{array}{l}11(17 \%) \\
25(39 \%) \\
10(15 \%) \\
10(15 \%) \\
27(42 \%)\end{array}$ \\
\hline & \multicolumn{2}{|c|}{ No. (\%) patients with GUD } \\
\hline & $\operatorname{Men}(n=78)$ & Women $(n=12)$ \\
\hline $\begin{array}{l}\text { Spirochaetes } \\
\text { H ducreyi } \\
\text { Yeasts } \\
\text { HSV antigen }\end{array}$ & $\begin{array}{r}10(13 \%) \\
22(28 \%) \\
8(10 \%) \\
15(19 \%)\end{array}$ & $\begin{array}{l}0 \\
0 \\
3(25 \%) \\
2(17 \%)\end{array}$ \\
\hline
\end{tabular}

with antibiotics at a rural health centre. Cotrimoxazole had been given to $67(28 \%)$ GUD patients and $34(17 \%)$ patients with discharge. Other antibiotics frequently given to GUD patients were penicillin (55 patients) and tetracycline (20 patients), while for patients with a discharge, 29 had received penicillin, 20 had received kanamycin and 20 had received metronidazole.

\section{Microbiology}

Specimens were collected from 104 men and 72 women, that is, $38 \%$ of all STD patients during the study period. Of the men, 68 (65\%) presented with GUD, 26 (25\%) with discharge and $10(10 \%)$ with both. Of the women $60(83 \%)$ had a discharge, $7(10 \%)$ had ulcers and $5(7 \%)$ had both.

Gonococci were isolated from 34/101 (34\%) patients with a discharge, and significantly more frequently from men (table 3 ). $\beta$ lactamase activity was shown by $21(62 \%)$ isolates, and $6(18 \%)$ showed resistance to tetracycline. Amongst women with a discharge, yeasts and $T$ vaginalis were the most frequently detected pathogens. The great majority of yeasts were Candida albicans, but $C$ kreusi and Torulopsis glabrata were occasionally found. Chlamydial antigen was detected in 13/101 patients with a discharge, and $G$ vaginalis was isolated from 10 women.

$H$ ducreyi was isolated only from men, being recovered from $28 \%$ of all ulcers, but from $46 \%$ ulcers that were described as painful. Spirochaetes also were only identified in specimens from men, with $8 / 32(25 \%)$ painless ulcers being positive by dark ground microscopy compared with $2 / 47$ (4\%) painful ulcers $(p<0.05)$. Yeasts were commonly isolated from ulcer fluids from both men and women, and in men they were associated with "rhagades" and itchiness of the glans. HSV antigen was detected in $17 / 90$ men and women with genital ulcers, while spirochaetes were found only in ulcer fluids from men (table 3).

\section{Syphilis serology}

There was generally good agreement between the results of the two specific Treponema pallidum tests, with discrepant results in only $27(15 \%)$ cases. There was less agreement between RPR and either TPHA (66 discrepant results) or FTA-Abs (63 discrepant 
Table 5 Co-infections in HIV-1 positive and negative patients

\begin{tabular}{|c|c|c|c|}
\hline Organism/test & $H I V-1+v e$ & $\begin{array}{c}\text { No. (\%) with positive culture/test } \\
\text { HIV }-1 \text {-ve }\end{array}$ & $p$ \\
\hline $\begin{array}{l}N \text { gonorrhoeae } \\
T \text { vaginalis } \\
\text { Yeasts }^{\star} \\
\text { Chlamydia antigen }{ }^{\star} \\
\text { G vaginalist } \\
\text { H ducreyi } \neq \\
\text { HSV antigen } \ddagger \\
\text { Spirochaetes } \ddagger \\
\text { Yeasts } \ddagger\end{array}$ & $\begin{aligned} 19(31 \%) \\
17(27 \%) \\
23(37 \%) \\
4(7 \%) \\
7(17 \%) \\
17(28 \%) \\
13(22 \%) \\
6(10 \%) \\
8(13 \%)\end{aligned}$ & $\begin{array}{r}15(39 \%) \\
11(28 \%) \\
4(10 \%) \\
9(23 \%) \\
3(13 \%) \\
5(17 \%) \\
4(13 \%) \\
4(13 \%) \\
3(10 \%)\end{array}$ & $\begin{array}{l}\text { NS } \\
\text { NS } \\
<0.05 \\
<0.05 \\
\text { NS } \\
\text { NS } \\
\text { NS } \\
\text { NS } \\
\text { NS }\end{array}$ \\
\hline
\end{tabular}

${ }^{\star}$ Discharge ( $\left.\mathrm{n}=62 \mathrm{HIV}+\mathrm{ve}, 39 \mathrm{HIV}-\mathrm{ve}\right)$

Discharge in women ( $n=42 \mathrm{HIV}+\mathrm{ve}, 23 \mathrm{HIV}-\mathrm{ve}$ )

fUlcer ( $n=60 \mathrm{HIV}+\mathrm{ve}, 30 \mathrm{HIV}-\mathrm{ve}$ )

results). Seven of the 10 sera from patients with spirochaete-positive ulcers were positive by FTA-Abs, compared with four positive by TPHA and five positive by RPR. The syphilis serology results are summarised in table 4.

\section{HIV serology}

Antibodies to HIV-1 were found in $47(69 \%)$ women and $63(61 \%)$ men. Amongst HIV-1 positive men, $49(78 \%)$ had a previous STD history compared with 20 (49\%) HIV-1 negative men $(p<0.01)$. Generalised lymphadenopathy was noted for $47(75 \%)$ men subsequently found HIV-1 positive, compared with 20 (49\%) HIV-1 negative men $(p<0.01)$. Lymphadenopathy was however found in a smaller proportion of HIV-1 positive women $(19 / 47,40 \%)$, and not statistically different from that in HIV-1 negative women $(6 / 25,24 \%)$. HIV-1 positive serology was found with $22(88 \%)$ unmarried women compared with 25 (53\%) married women $(p<0.01)$.

Apart from these there were no epidemiological or clinical associations with positive HIV-1 serology. In particular there was no association with current GUD, with 60 (67\%) GUD patients being HIV-1 positive compared with $50(58 \%)$ patients without ulcers.

\section{HIV and other STDs}

Except for yeast infections there was no detectable association between HIV-1 serology and STDs detected in genital tract specimens (table 5). Despite numbers being small, a positive Chlamydia test occurred more frequently in HIV-1 negative than positive patients.

There was good correlation between HIV1 positive serology and serological evidence of current or past syphilis, with $48 / 57$ (84\%) FTA-Abs positive sera having antibodies to HIV-1, compared with 62/119 (52\%) FTAAbs negative sera $(p<0.01)$. There was less strong correlation with TPHA positive sera, $45 / 58$ ( $76 \%$ ) being HIV-1 positive compared with $65 / 118(56 \%)$ TPHA negative sera $(\mathrm{p}<0.05)$ and there was no significant correlation with RPR, with 46/66 (70\%) RPR positive sera being HIV-1 positive compared with 64/1 10 (58\%) RPR negative sera. Thirty nine (35\%) of the HIV-1 positive sera showed evidence of active syphilis (positive RPR plus at least one of the two specific tests), compared with $8 / 66$ (12\%) HIV-1 negative sera $(p<0.01)$.

\section{Discussion}

This study shows the high prevalence of STDs in a small rural town in Zimbabwe. During the three months of study, STDs were the most common outpatient condition seen in adults, with the 20-29 year age group being seen in numbers disproportionate to their numbers in the community. The male:female patient ratio was $2 \cdot 2$, while in the district it is varies from 0.8 to 1.2 in different age groups. ${ }^{4}$ Although mainly a commercial and subsistence farming area, Karoi is also on the main truck route to Zambia, Malawi and other countries to the north, and a high prevalence of STDs has been reported in long distance truck drivers in East Africa. ${ }^{8}$ While none of these patients was a driver, these transient men may have contributed to the STD burden of the community by infecting local women. It is clear from other studies in Africa $^{910}$ that prostitutes are a significant source of STD. There were insufficient resources for gathering of detailed behavioural data, but full time prostitution is rare in Karoi, while paid casual sex occurs frequently. The finding that amongst men the most significant risk factor for any STD was employment, with $66 \%$ male STD patients being employed compared with $27 \%$ for the district, ${ }^{4}$ suggests that paid sex is a significant factor in transmission.

Clinically, the most common findings were of GUD in men and genital discharge in women, as is frequent in Africa. ${ }^{11-13}$ The prevalence of genital warts was similar to that seen in STD patients and pregnant women in Harare, ${ }^{511}$ but warts were recorded in less than $1 \%$ STD patients in Malawi ${ }^{12}$ and were not found in any of 193 pregnant women in a rural clinic in S. Africa. ${ }^{13}$ The reason for this apparently high prevalence in Zimbabwe is not known.

Of particular note in these STD patients was the high prevalence of HIV-1 seropositivity. There are few published studies on the prevalence of HIV in the general population of Zimbabwe, though data from pregnant women presenting at various clinics in Harare indicate a seroprevalence of $15-20 \%$ in this selected group. ${ }^{14}$ In men who have been deferred as blood donors because of risk behaviour, an HIV seroprevalence of $36 \%$ has been recorded in our laboratory (unpublished data). Our data demonstrate a much higher seroprevalence in STD patients attending a rural hospital, indicating the need for integration of STD and AIDS preventive programmes.

We found generalised lymphadenopathy to be a sensitive (though not specific) indicator of HIV-1 infection only in men. Since clinical diagnosis of HIV infection is normal in many developing countries because of the high cost of laboratory tests, more detailed investigations to determine differences in presentation in men and women are needed. Oral candidiasis was uncommon, despite the high prevalence of HIV-1 seropositivity, though this may be because these patients were still in early stages of infection, with adequate immunity. 
GUD is known, from a number of African studies, to be a significant risk factor in HIV transmission, ${ }^{15-17}$ though in many of these studies the prevalence of HIV infection was much lower than in Karoi. The relationship between GUD and HIV transmission is complex and dynamic, and it has been noted that cross sectional studies may be inadequate to clearly demonstrate this relationship. ${ }^{9}$ Previous episodes of STD were frequently reported by the patients in Karoi, and thus there may have been exposure to HIV during prior GUD episodes. In men, chancroid was the most common cause of GUD, with $H$ ducreyi being isolated from $46 \%$ ulcers diagnosed clinically as chancroid. This was substantially lower than found in GUD in men in an urban clinic in S. Africa, ${ }^{18}$ but conditions for the isolation and growth of $H$ ducreyi were less than optimal with the limited facilities at Karoi. Microscopic examinations of the ulcer fluid often showed typical organisms, but these failed to grow. Improvements in diagnostic technique are needed in order to more clearly define the epidemiology of chancroid in rural areas.

In women with a discharge, trichomoniasis was one of the most frequent diagnoses, and this is in keeping with other studies in Zimbabwe. ${ }^{519}$ Gonococcal infection was demonstrated in nearly two thirds of discharges in men, and in about $17 \%$ of discharges in women. The high frequency of penicillin resistance is in keeping with reports from Harare, but evidence of the emergence of tetracycline resistance is disquieting, as this has not previously been experienced. ${ }^{20}$ There was a relative absence of $G$ vaginalis in women with discharge, whether diagnosed on the basis of culture or by the presence of clue cells, and this is in contrast with findings in Harare. ${ }^{5}$ In this study, women who had been treated with antibiotics were excluded, whereas at the referral centre in Harare many of the women had received treatment before referral, and the two groups are therefore not strictly comparable.

In this study we found evidence of chlamydial infection to be negatively associated with evidence of HIV-1 infection. This is in marked contrast to other cross sectional studies which demonstrate no association ${ }^{910}$ or longitudinal studies in which chlamydial infection was shown to be a risk factor in HIV-1 acquisition. ${ }^{17}$

There was evidence of primary syphilis, with spirochaetes in ulcer fluid, in $13 \%$ men with GUD, and $27 \%$ sera tested showed evidence of active syphilis. Studies elsewhere in Africa have shown the prevalence of active syphilis to vary from $47 \%$ in prostitutes in Somalia to less than $1 \%$ of pregnant women in Nigeria. ${ }^{2122}$ Syphilis is regarded as an important cofactor in HIV transmission, ${ }^{17}$ and our finding of a correlation between syphilis and HIV-1 seropositivity was not unexpected. We found only 17 patients with ulcer fluid containing HSV antigen, and these numbers were too small to detect an association with other STDs.
In summary our findings were that in Karoi District STDs are an important health problem, with chancroid, trichomoniasis, gonorrhoea and syphilis being prevalent. The high prevalence of HIV-1 infection in STD patients is indicative of the relationship between HIV and STDs, and supports arguments for the integration of both AIDS and STD prevention programmes if control is to be achieved. It is clear that STDs are at least as common in rural as in urban communities, and control measures would therefore need to be established countrywide. Targeting the employed through the work-place would appear to be an effective means of delivery of such programmes.

The technical and administrative assistance of $\mathrm{Mr} \mathrm{N}$ Kondo is greatly appreciated. This study received the support of the Mashonaland West Principal Medical Director, Dr Katito, and of the Medical Research Council of Zimbabwe. Finance was provided by the University of Zimbabwe Research Board and Medicus Mundi.

1 Latif AS. Sexually transmitted diseases in Africa. Genitourin Med 1990;66:235-7.

2 Annual Report of the Medical Officer of Health. City of Harare. 1990.

3 Annual Report of the Medical Officer of Health. City of Bulawayo. 1990.

4 District Population Data. Central Statistical Office. Government of Zimbabwe. Harare. 1989.

5 Mason PR, Gwanzura L, Latif AS, Marowa E. Genital infections in women attending a genitourinary clinic in Harare, Zimbabwe. Genitourin Med 1990;66:178-81.

6 Sottnek FO, Biddle JW, Kraus SJ, et al. Isolation and cultivation of Haemophilus ducreyi in a clinical study. $\mathcal{F}$ Clin tivation of Haemophilus ducre
Microbiol 1980;12:170-4.

7 Dylewski J, Nsanze H, Maitha G, Ronald AR. Laboratory diagnosis of Haemophilus ducreyi: sensitivity of culture diagnosis of Haemophilus ducreyi: sensitivity
media. Diag Microbiol Inf Dis 1986;4:241-5.

8 Bwayo JJ, Omooi AM, Mutere AW, et al. Long distance truck drivers: 1 . Prevalence of sexually transmitted diseases (STDs). E Afr Med f 1991;68:425-9.

9 Nzila N, Laga $M$, Thiam MA, et al. HIV and other sexually transmitted diseases among female prostitutes in Kinshasa. AIDS 1991;5:715-21.

10 Simonsen JN, Plummer FA, Ngugi EN, et al. HIV infection among lower socioeconomic strata prostitutes in Nairobi. AIDS 1990;4:139-44.

11 Latif AS, Bvumbe S, Muongerwa J, et al. Sexually transmitted diseases in pregnant women in Harare, Zimbabwe. Afr $\mathcal{F}$ Sex Trans Dis 1984;1:21-3.

12 Kristensen JK. The prevalence of symptomatic sexually transmitted diseases and human immunodeficiency transmitted diseases and human immunodeficiency virus infection

13 O'Farrell N, Hoosen AA, Kharsany ABM, Van Den Ende $\mathrm{J}$. Sexually transmitted pathogens in pregnant women in a rural South African community. Genitourin Med 1989;65:276-80.

14 Mahommed K, Kasule J, Makuyana D, et al. Seroprevalence of HIV infection amongst antenatal women in greater Harare, Zimbabwe. Centr Afr $\mathcal{F}$ Med 1991; 37:322-5.

15 Nsubuga $P$, Mugerwa $R$, Nsibami J, et al. The association of genital ulcer diseases with HIV infection at a dermatology-STD clinic in Uganda. $₹$ AIDS 1990;3:1002-5.

16 Plummer FA, Simonsen JN, Cameron DW, et al. Cofactors in male-female sexual transmission of human immunodeficiency virus type 1. F Inf Dis 1991;163: immun 233 .

17 Latif AS, Katzenstein DA, Bassett MT, et al. Genital ulcers and transmission of HIV among couples in Zimbabwe. AIDS 1989;3:519-23.

18 Dangor Y, Fehler G, Exposto FD, Koornhof HJ. Causes and treatment of sexually acquired genital ulceration in southern Africa. S Afr Med $¥$ 1989;76:339-41.

19 Mason PR, Patterson BA, Latif AS. Epidemiology and clinical diagnosis of Trichomonas vaginalis infection in Zimbabwe. Centr Afr $\mathcal{F}$ Med 1983;29:53-6.

20 Mason PR, Gwanzura L, Latif AS, Marowa E. Antimicrobial susceptibility of Neisseria garowa E. Antimicrobial susceptibility of Neisseria gonorrhoeae in Dis 1990;17:63-6.

21 Ahmed HJ, Omar K, Adan SY, et al. Syphilis and human immunodeficiency virus seroconversion during a 6month follow up of female prostitutes in Mogadishu, Somalia. Int $\mathcal{F}$ STD AIDS 1991;2:119-23.

22 Gini PC, Chukuddebelu WO, Njoku-Obi AN. Antenatal screening for syphilis at the University of Nigeria Teaching Hospital, Enugu, Nigeria-a six year survey. Int $\mathcal{F}$ Gynaecol Obstet 1989;29:321-4. 